\title{
Children with Special Educational Needs in Suhareka: Number, Characteristics and School Career
}

\author{
Fatime Hoxha ${ }^{*}$, Shemsi Morina \\ Faculty of Primary Education, University of Prizren, Kosovo \\ Received July 25, 2020; Revised September 17, 2020; Accepted September 29, 2020
}

\section{Cite This Paper in the following Citation Styles}

(a): [1] Fatime Hoxha, Shemsi Morina, "Children with Special Educational Needs in Suhareka: Number, Characteristics and School Career," Universal Journal of Educational Research, Vol. 8, No. 11B, pp. 5888 - 5893, 2020. DOI: 10.13189/ujer.2020.082222.

(b): Fatime Hoxha, Shemsi Morina (2020). Children with Special Educational Needs in Suhareka: Number, Characteristics and School Career. Universal Journal of Educational Research, 8(11B), 5888 - 5893. DOI: 10.13189/ujer.2020.082222.

Copyright $\odot 2020$ by authors, all rights reserved. Authors agree that this article remains permanently open access under the terms of the Creative Commons Attribution License 4.0 International License

\begin{abstract}
In this paper we have analyzed 40 villages of the municipality of Suhareka. In the years after the war, the number of newborn children with physical and mental health problems has greatly increased. Such problems cause changes in society and are an important and necessary object of study to be given the merit of study. Recently, we have witnessed an increase in the number of children with special needs, ranging from speech impediments to physical barriers to changes in the biological structures of the human body. From our analysis, it turns out that in Suhareka, the place with the largest number of children with disorders is Bllacë. Suhareka; the place I study is a place not too big as a surface and either not mixed with communities, so their involvement is very small, which makes the analysis very specific and deals in detail with the community Albanian who has experienced these changes over time. In the local registry, all these children have a recommendation for special treatment; and as can be seen from the survey with parents, very few of these recommendations have been followed. The main disorder that the children in this study suffer from was intellectual disorder. From these diseases the most affected by what we have analyzed turns out to be the male.
\end{abstract}

Keywords Disability, Inclusive, Self-confidence, Respect for Rights

\section{Introduction}

In recent years, we have seen an increase in the number of newborn sick children; and there is an awareness of parents and an adaptation of the infrastructure for the realization of intellectual achievements. First of all, the realization of such a system should depend on the country and must be preceded by a detailed analysis of the community and parental acceptability.

We know the importance of the voice of children with special needs, considering them the same as others and developing them as citizens with their rights, as well as their equal treatment with others, their social and intellectual assistance and physical development [1]. Education is a great system that involves the multifaceted development of children and their preparation to face the challenges that await them in the future. Of particular importance is the formation of their character as well as the acceptance of students with special needs in their society. The provision of services in educational systems should also include children with special needs. While accepting them in the classroom and helping children with special needs to develop in various aspects, the other students should also be taught that differences in life exist but they should never be seen as obstacles. In recent years, the education system has begun to provide opportunities for children with special needs to access public schools by accessing the necessary infrastructure in public schools [2].

Education is very important for all children, but it helps more children with special needs. A pre-school program will help parents identify their children with disabilities, so that most of them identify when they start school. Early identification is a great help for both the child and the 
parents, helping them out starting as soon as possible the necessary training [3].

So in the same line, the importance of educating parents of children with special needs should be emphasized, as this would help them to initially accept themselves not to feel ashamed and start providing assistance for their children as soon as possible. In these cases, school represents a new and changing context within the life of a child [3]. The municipality of Suhareka $\left(42.3625^{\circ} \mathrm{N}\right.$, $20.8319^{\circ} \mathrm{E}$ ) is located in south-eastern Kosovo. It covers an area of approximately $361 \mathrm{~km}^{2}$ and includes Suhareka/ town and 42 villages. According to the Kosovo Population and Housing Census 2011 the total population is 59,722. There are 30 primary schools with 10,702 pupils and 702 teachers; two (2) secondary schools with 3,246 students and 161 teachers; and one (1) kindergarten with 81 children and three (3) teachers (source: municipal directorate of education). The main of disorders in Suhareka municipality are: Autism, epilepsy, physical disability, ADHD, Intellectual disability, down syndrome, visual impairments, etc. Autism is a neuropsychiatric disorder characterized by severe and sustained impairment in social interaction, deviance in communication, and patterns of behavior and interest that are restricted, stereotyped, or both. Onset is generally before age 3 years" (Kanner, 1992). "Autism spectrum disorder (ASD) and autism are both general terms for a cluster of complex disorders of brain development. These disorders are categorized, in varying degrees, by having problems in social interaction, verbal and nonverbal communication and repetitive behaviors" [4]. Epilepsy has a focal origin in the brain. It manifests from the site of the focus and regions into which the discharges spread. Most of the cases are primary (idiopathic); some may be secondary to trauma/surgery on head, intracranial tumor, tuberculoma, cysticercosis, cerebral ischemia [5]. Individuals with an intellectual disability have neurodevelopmental deficits characterized by limitations in intellectual functioning and adaptive behavior. These disabilities originate and manifest before the age of 18 and can be associated with a considerable number of related and co-occurring problems including mental health (e.g., depression, and anxiety), neurodevelopmental (e.g., autism spectrum disorders, and attention deficit hyperactivity disorder), as well as neurological (e.g., infantile cerebral palsy) and medical conditions (e.g., meningitis) [6]. A physical disability is the long-term loss or impairment of part of a person's body function, resulting in a limitation of physical functioning, mobility, dexterity or stamina. Due to the functional loss the person will experience the inability to perform normal movements of the body, such as walking and mobility, sitting and standing, use of hands and arms, muscle control, etc [5]. Attention Deficit and Hyperactivity Disorder (ADHD) is a neurodevelopment disorder with child-onset, characterized by inattention, hyperactivity, and impulsivity. Several of the individual's ADHD symptoms must be present prior to age 12 and lead to functional impairment on multiple levels of life (family, social, academic, and working life). The predominance of symptoms varies among individuals and at the same time in the same individual, giving rise to 3 different configurations of the disease:

- predominantly inattentive;

- $\quad$ redominantly hyperactive-impulsive;

- Mixed clinical presentation of the two domains [7].

Down syndrome is the most common chromosomal abnormality worldwide and is characterized by a spectrum of multisystem anomalies Chromosome 21, of which there are three copies in Down syndrome, containing fewer functional genes than the other autosomes allowing affected individuals to survive, in contrast with other trisomy. Interestingly, not all genes on chromosome 21 are involved in the Down syndrome phenotype. Other parts of the genome also contribute to the condition, as some proteins produced by genes encoded on chromosome 21 are involved in transcription [8]. Visual impairments definition is related with the concepts of visual acuity and visual field. Visual acuity is the ability to see the objects from a certain distance and to distinguish the details. Different sizes of letters, numbers and symbols can be read and measured from a distance of 6.10 meters (20 feet) in general [9].

In recent years, our society has a very good approach for people with special needs; tolerance towards them has increased not only by being treated better but by giving them equal rights like other people, but including them doing what they can work based on their ability. But whenever there may be different cases, both in society or at school where a child feels offended, but we should not try to find out how he or she is actually feeling, but we should not think of what a person with a disability can offend., but for the fact that any child, can persecuted. If there is a bully on this team, then, whether a student is incompetent or not, the victim will be found. Therefore, attention should be paid not to hypothetical disability promotion, but to the problem of bullying [10]. There can be physical and social barriers which deprive of the children's rights to education, but there can also be social and pedagogical barriers which invade the children's right in education, that is the right to participate in all aspects of their education. Finally, all such barriers concur to delimit children's rights through education, which is achieving outcomes of learning that expand children's capabilities.

We do not suggest that these children be competent in any decision regarding matters in the classroom or school, but we do suggest a support and some guidance for them that would greatly help them both in personal welfare and needs [11 - 13].

In this paper we analyzed the various diseases that primary school children suffer from, where the most common were: Autism, epilepsy, intellectual disabilities, physical disability, ADHD, down syndrome, and visual impairments, etc. The purpose of the study, among other 
things, is to determine how much our society has progressed in accepting students with special needs in society and normal schools; and how much their number has increased over the years.

\section{Results}

In this research, we have used a quantitative approach. "The quantitative approach follows a range of exploring procedures that are inflexible and prior structured and defined, which aim for the determination of the quantity of change in a phenomenon; it focuses on measuring the variables and process objectivity; it trusts the support of the truth on the basis of the sample size; it gives validity and credence to findings and it imparts the findings in the analytic and synthetic form, drawing conclusions and meanings that can be generalized."

We also used comparative analysis to figure out the diseases affected students the most.

As you can see in figure 1, we have analyzed the villages of the municipality of Suhareka which has resulted in the largest number of children with disorders; and it shows that it is the village of Bllace; and we have noticed that this village is the village with the largest number of inhabitants also of great importance plays the role of parental education, where most of them were not educated and their marital status is moderately poor. From the interview conducted with the parents from this village, it showed that 75 percent of them had completed their studies up to the 4th grade, and some of them were also divorced from their partners; this very painful interview is also an important fact that the village Bllace to result in the largest number of children with disorders. This also shows the lack of interest of parents to help them in their studies, and the decline in the learning success of these children as well as the non-functioning of the didactic triangle in the educational process.

As described in figure 2, it is shown that the city of Suhareka or its villages have had a request or recommendation for training of students with disorders and it has resulted that Suhareka has a higher number of recommendations for training of students. We also asked questions about what they think about the training of their children in the relevant institutions, whether they think that over time this training would help their children and improve them, and how they have responded to the recommendation of municipality. We realized that most of the answers were negative.

We have also seen in the analysis that some of them are attending the planned training.

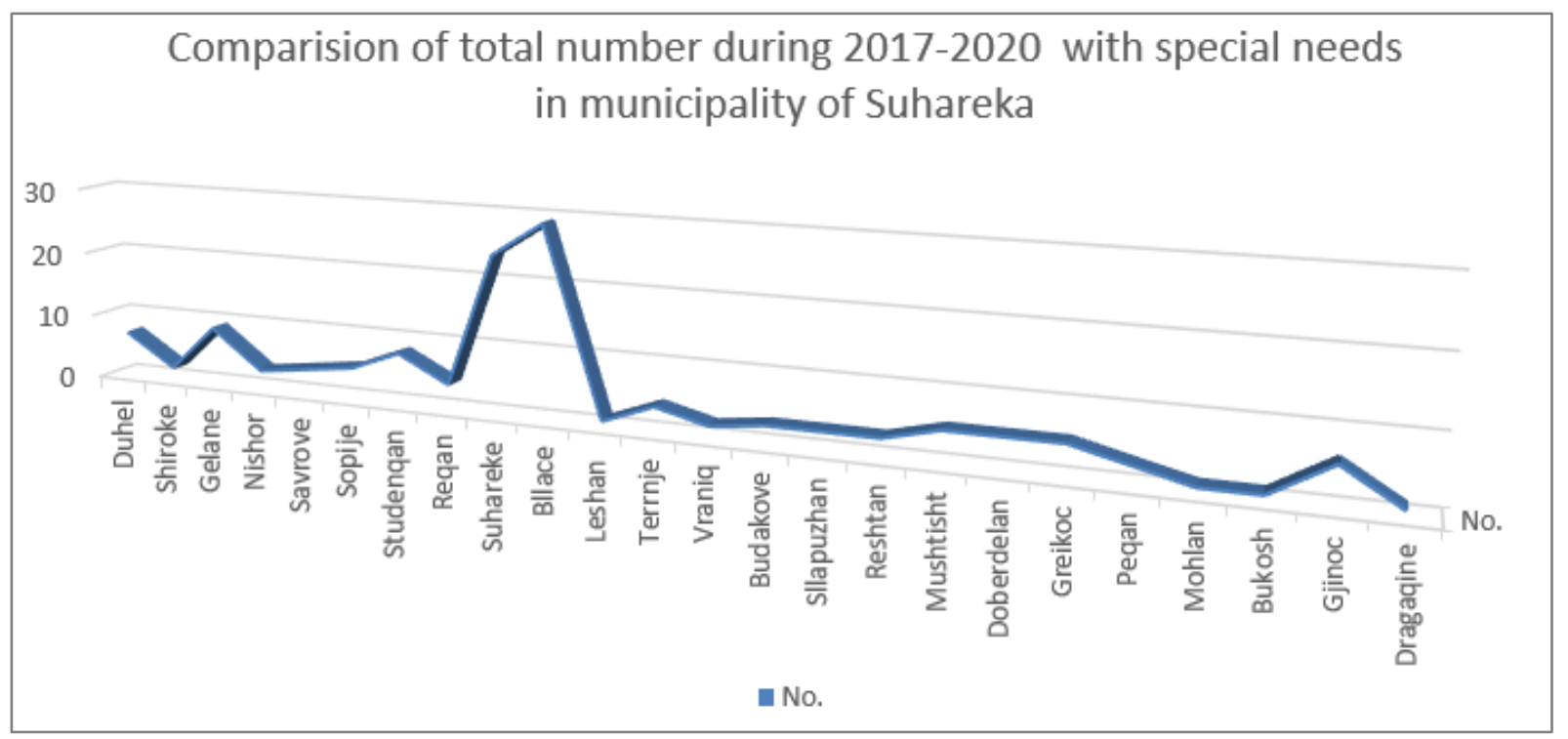

Figure 1. Statistic which of the villages has more children with disorders 


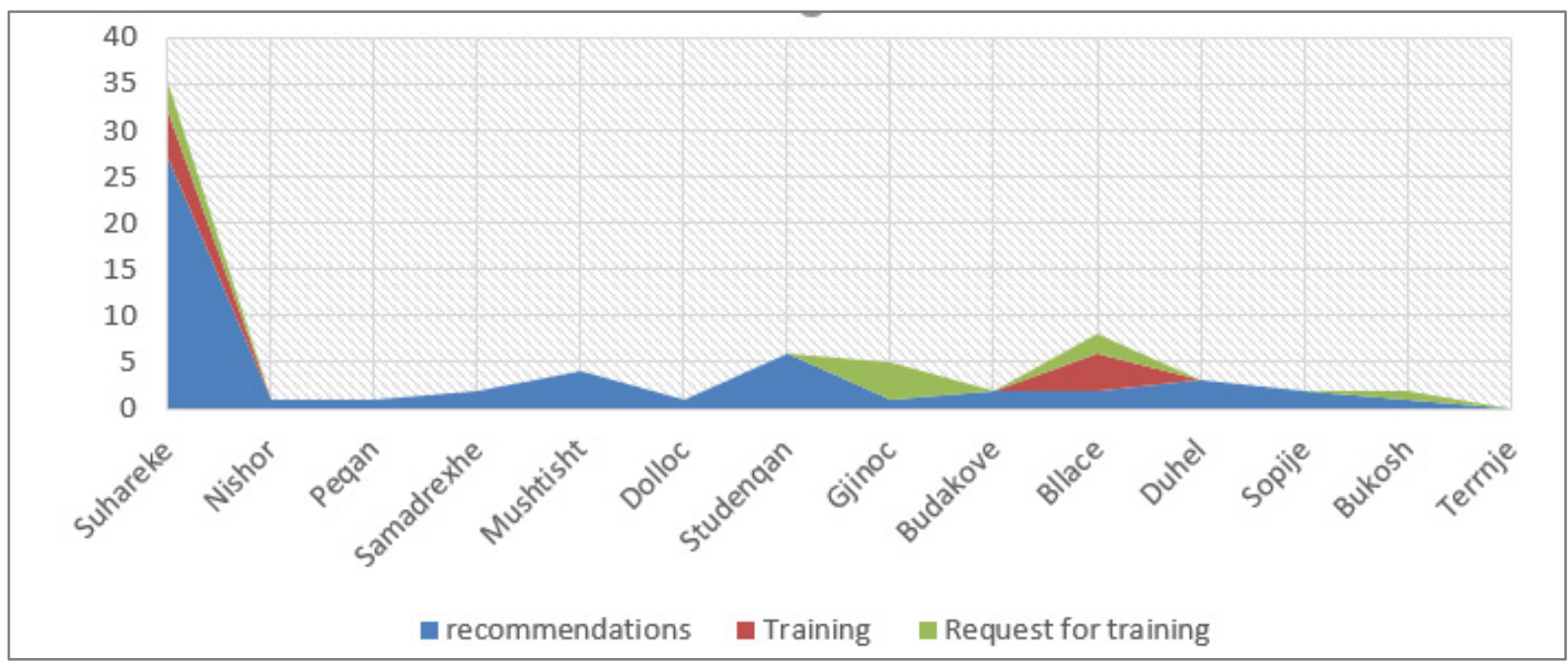

Figure 2. Statistic of recommendations, training, and request for training for children with disabilities in Suhareka municipality during 2017-2020

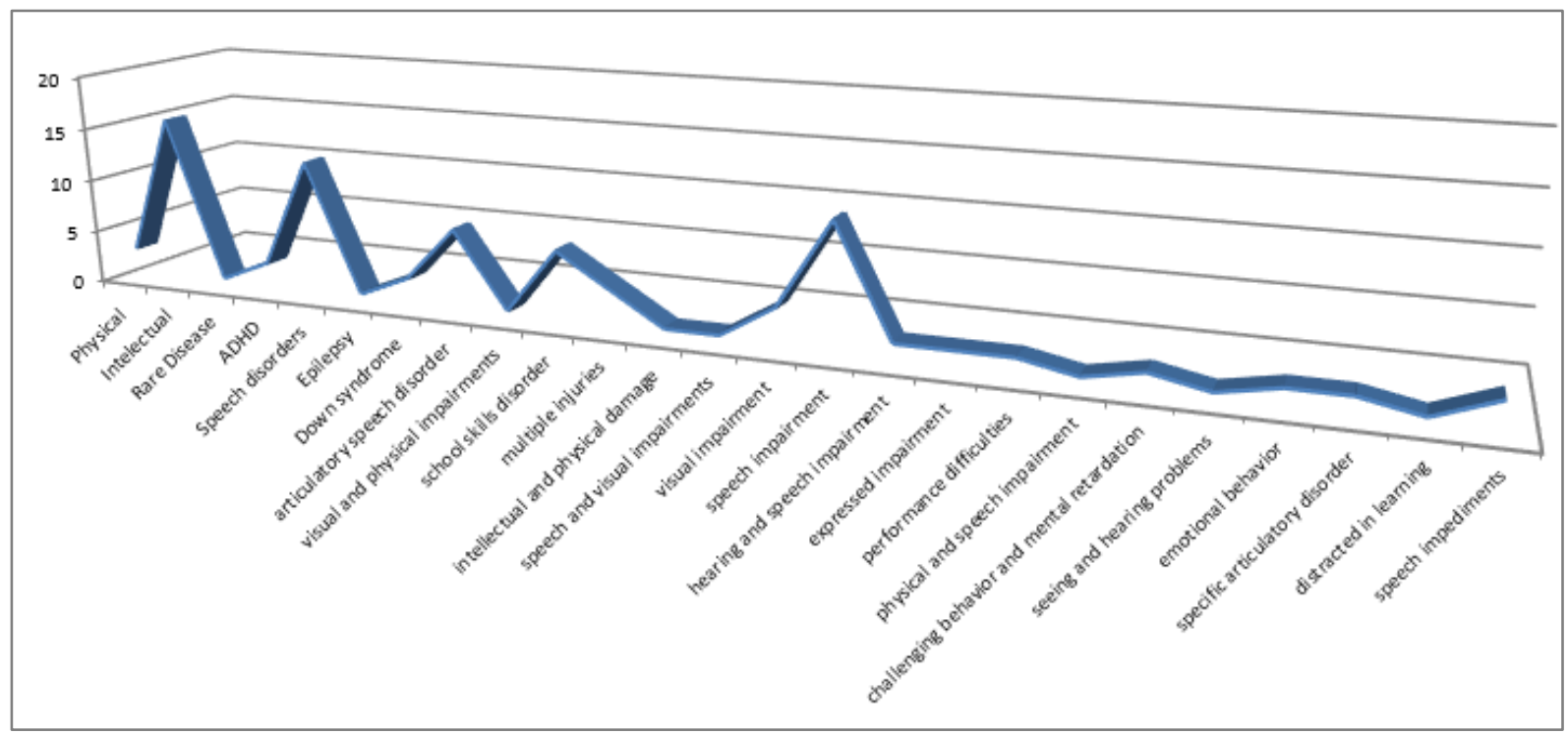

Figure 3. Types of disabilities in child in Suhareka municipality from 2017-2020

In figure 3, we have presented the types of diseases that we have encountered in the analysis of students in the municipality of Suhareka and its villages; we have noticed various diseases by which children are affected and the greater number of students has suffered from intellectual disability, but these children are involved in the educational process and are part of normal schools. The number of children with physical injuries was also close, and some of the students with the most severe physical injuries were not included in normal schools due to inadequate infrastructure.

In this diagram we have presented the analysis of which of the gender is more affected by the disorders and we have seen that the male is more affected than the female. 


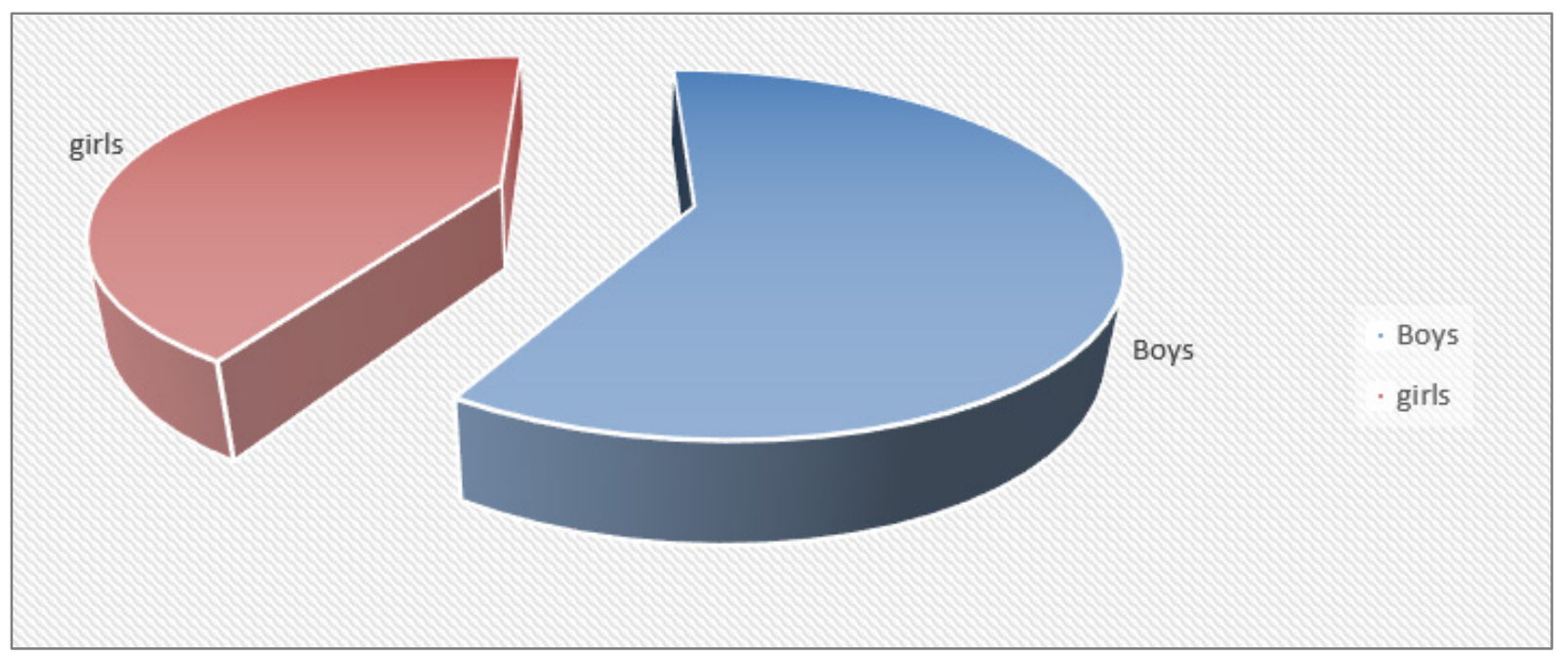

Figure 4. Comparative statistical in gender during 2017-2020

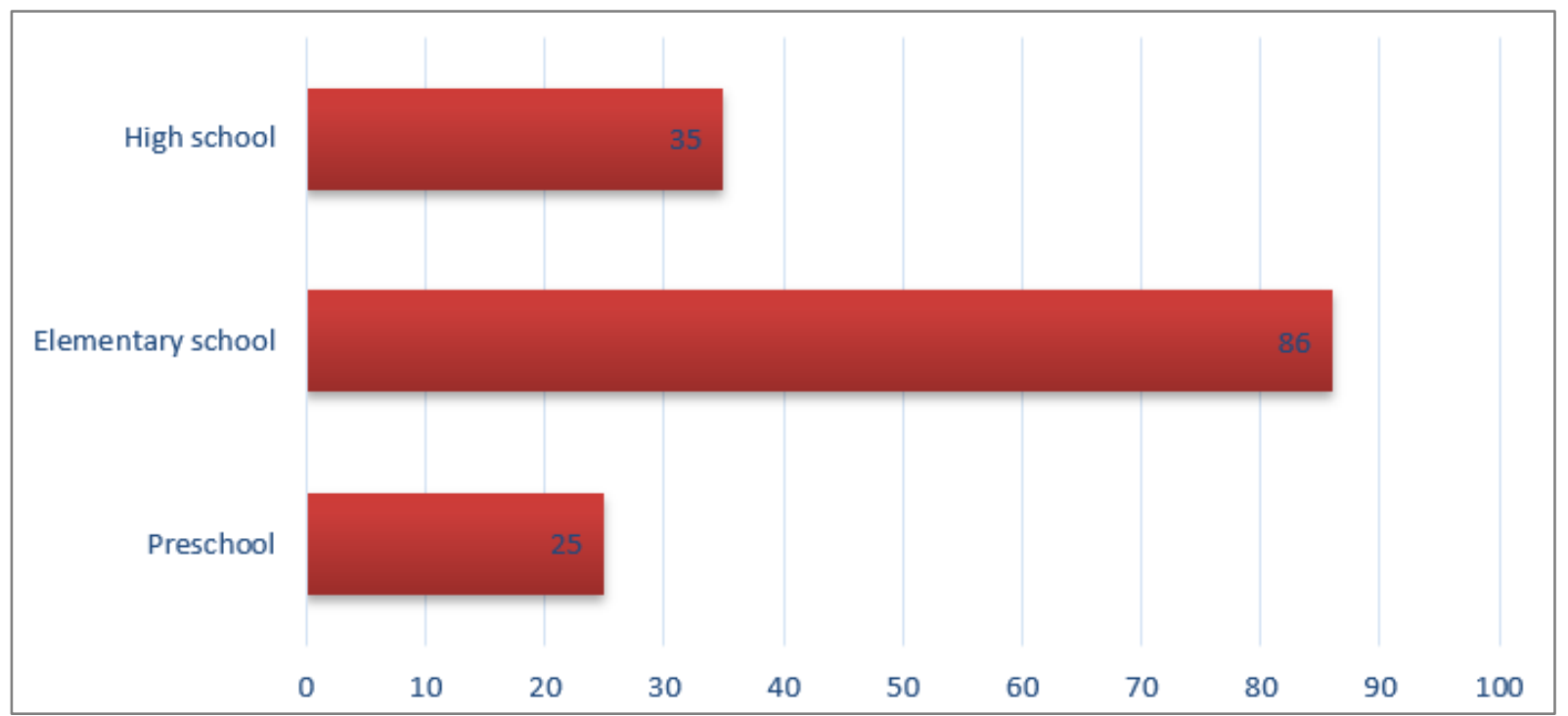

Figure 5. The structure of students affected at each school level

Here we also found that the number of males was higher than the female, described in figure 5 . We found out that most of the children did not have one parent, or had parents who suffered trauma during the war. Some of them were adapted, and some of those children who live in a family where domestic violence is exercised, so recalling the largest number of intellectual injuries which also play a role in these factors, and have affected this gender in recent years. We found out that there were 86 boys and 61 girls with different disabilities.

In this diagram we have presented the number of students with disorders at each school level, where in the primary school a total of 36 students, in the high school 35 students and in the preschool 25 students.

\section{Conclusions}

The total number of students from public preschool education to public pre-university institutions is 11,461 ; and students with disabilities are 147 , where 86 were male, 61 females and as percentage $1.28 \%$ of total students in Suhareka municipality.

From the analysis done it is seen that the most common disability is intellectual impairment, another element that we have analyzed is how much the number has increased from year to year and we have damage noticed that we have a gradual increase from 2016 to 2019.

We also analyzed the school level of the largest number of children affected by various disorders and found that primary schools have the highest number of children with disorders; out of 147 cases of children affected, 9 of them were attending the recommended training, a very small number compared to the number of children with disabilities, which means that some of the parents did not accept as a possibility that their children will receive adequate training. They could socialize and be equal to 
other children.

In conclusion, we can say that considering the inadmissibility of parents for adequate special training of children it is necessary to start now with the involvement of assistants-psychologists at each school-class level and the adaptation of the infrastructure for students with physical problems at all schools. This would mean their inclusion in regular schools and equal opportunities with other sections of society.

Schools should be provided with assistive psychological assistance is that the very fact from the surveys conducted with the parents of such children, which shows that they do not accept special education, as they think that over time these disorders will be fixed. And to join normal schools the need for classroom assistants is essential, these data are verified by the MDE- municipal directorate of education. Finally, we suggest that teacher training is necessary as this would help the access of these children. It would also be recommended for the municipal directorate of education start implementing inclusion, given that this number is growing and parents are reluctant to send their children to special institutions.

\section{REFERENCES}

[1] Van der Veen, I., Smeets, E. and Derriks, M. (2010). Children with special educational needs in the Netherlands: number, characteristics and school career, Educational Research, Vol. 52, No. pp. 15-43.

[2] Devecchi C., Rose R., Shevlin M. (2014). Education and the Capabilities of Children with Special Needs. Agency and Participation in Childhood and Youth.
[3] Aron L., Loprest P. (2012). Disability and the Education System. THE FUTURE OF CHILDREN. 22(1) 97-122.

[4] Ghaneshirazi Z., Moghimi E. (2018). Autism Spectrum Disorder. Research gate review 145, no.8. 4-8.

[5] Upadhyay J., Upadhyay G, Joshi- Rana. A. (2019). Pharmacological potential of genus Marchantia: A Review. Department of Pharmaceutical Sciences, Kumaun University Nainital, Nainital, Uttarakhand,

[6] Lee, K., Cascella, M., \& Marwaha, R. (2020). Intellectual disability. Treasure Island, FL: StatPearls Publishing.

[7] Raponi, A., Giupponi, G., \& Conca, A. (2020). Adult ADHD. Clinical Management Issues, 14(1).

[8] Postolache L., De Jong C., Casimir G. Ophthalmic Genetics. (2020). Illustration of tessellation in Down syndrome. Taylor \& Francis Group, LLC.

[9] Yanik T. Aslan I. (2014). Internationalization in shadow of globalization and some strategies at Agri Ibrahim Cecen University (ICUA). Department of Special Education Ibrahim Cecen A. University Agri, Turkey

[10] Fedulova, I., Ivanova, V., Atyukova, O. \& Nosov, V. (2019). Inclusive Education as a Basis for Sustainable Development of Society. Journal of Social Studies Education Research, 10(3), 118-135.

[11] https://ds.gpii.net/content/what-physical-disability

[12] Devecchi, C., Rose, R. \& Shevlin, M. (2015) 'Education and the capabilities of children with special needs.' In C. Sarojini-Hart, M. Biggeri \& B. Babic (eds), Agency and Participation in Childhood and Youth: International Applications of the Capability Approach in Schools and Beyond, pp. 1

[13] Gonca Erim, Müge Caferoğlu, "Determining the Motor Skills Development of Mentally Retarded Children through the Contribution of Visual Arts," Universal Journal of Educational Research, Vol. 5, No. 8, pp. 1300 - 1307, 2017. 